\title{
Performance on the Maintenance of Certification for Family Physicians (MC-FP) Examination: Comparison of Initial Certifiers with Experienced Physicians
}

\author{
Michael R. Peabody, PhD, Thomas R. O'Neill, PhD, and James C. Puffer, MD
}

Keywords: Bias, Certification, Clinical Competence

The perception that state-of-the-art clinical knowledge declines as a physician moves further away from formal training is prevalent. ${ }^{1}$ This perception is reinforced by a significant body of research. ${ }^{2-8}$ As a result, seasoned family physicians may have concerns that the American Board of Family Medicine's Maintenance of Certification for Family Physicians (MC-FP) examination may be biased against them. However, recent research has found that family physicians maintaining their certification performed better than recent graduates, with scores reaching their highest point approximately 30 years after their initial certification. ${ }^{1}$ The belief that the examination is biased against veteran physicians or merely fails to recognize their years of additional experience may be partially reinforced by only considering the MC-FP examination's passing rates without regard to the distribution of scores.

To illustrate, the April 2013 MC-FP results for US medical graduates who did not fail their most recent previous attempt, are described (Table 1, Figure 1, and Figure 2). Note that the minimum passing standard was 390 in 2013. Examinees meeting these criteria account for $73 \%$ of the examinees testing during this administration. The results

This article was externally peer reviewed.

Submitted 16 September 2014; revised 13 November 2014; accepted 21 November 2014.

From the American Board of Family Medicine, Lexington, KY.

Funding: none.

Conflict of interest: All three authors are employees of the American Board of Family Medicine.

Corresponding author: Michael R. Peabody, Ph.D., 1648 McGrathiana Parkway, Suite 550, Lexington, KY 405111247 (E-mail: mpeabody@theabfm.org).
Table 1. Pass Rates and Mean Scaled Score by Candidate Type (April 2013 Maintenance of Certification for Family Physicians [MC-FP])

\begin{tabular}{lccccc}
\hline & Fail & Pass & Total & Pass Rate & Mean Scaled Score \\
\hline CERT & 150 & 1,930 & 2,080 & $92.8 \%$ & 497 \\
RECERT & 936 & 7,954 & 8,890 & $89.5 \%$ & 515 \\
\hline
\end{tabular}

CERT, initial certification; RECERT, maintaining certification.

seem contradictory in that initial certifiers pass $(92.8 \%)$ at a higher rate than those maintaining their certification $(89.5 \%)$, but this group has a higher mean score by approximately 18 points (Table 1). If only the pass rate is considered, one would conclude that the initial certifiers perform better on the examination and that the examination might be biased against those attempting to maintain certi-

Figure 1. Normal distribution for first-time takers, US medical graduates on the April 2013 Maintenance of Certification for Family Physicians (MC-FP) examination.

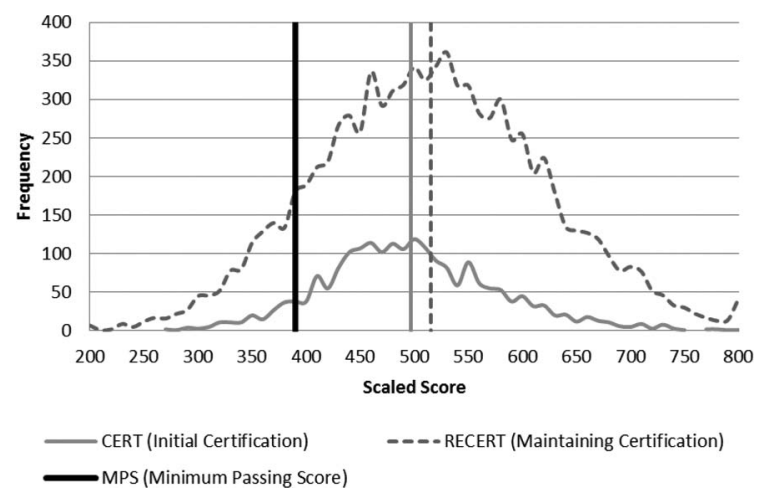


Figure 2. Inverse cumulative frequency distribution for first-time takers, US medical graduates on the April 2013 Maintenance of Certification for Family Physicians (MC-FP) examination.

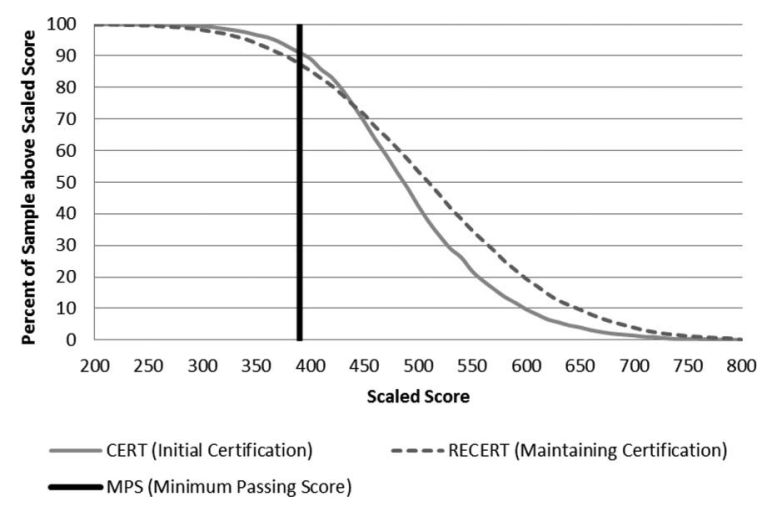

fication. If only the mean scores are considered, one would conclude that those attempting to maintain certification perform better on the examination and perhaps the examination is biased against initial certifiers. It seems that a more nuanced understanding is needed of what "performance" means. Figure 1 shows that on average recertifiers score higher than initial certifiers. It also shows that there are more recertifiers than initial certifiers and that some recertifiers score very poorly. The recertifier distribution extended down to 200 while the initial certifier line only went as low as 260 . To look at the scores from a slightly different perspective, we present an inverse cumulative frequency distribution (Figure 2). Please note that the lines cross at a score of 430. To the left of that point, initial certifiers score higher than recertifiers. To the right of that point, recertifiers score higher.

Figure 2 supports two common-sense concepts. The first is that residents, the initial certifiers, have a safety net on the examination. Before the examination, they have access to current best practices for a broad spectrum of topics and they have someone to whom they are accountable for their progress. If they do not meet the residency program's standards, they do not graduate. Essentially, a gatekeeper prevents the very low performers from testing until they are better prepared.

The second notion is that veteran physicians, as a group, have a substantial amount of experience that manifests itself positively on the examination; however, they do not have the safety net that the residents have. Sometimes veteran physicians limit their scope of practice and lose familiarity with those other domains. Other times, they fail to appropriately update their knowledge base due to time demands, inability to identify the areas they need to update, or they prefer to update other areas that are of greater interest to them. Taking the MC-FP examination is generally not an educational activity, but preparing for it definitely is. These results suggest that most veteran family physicians are not only able to maintain their clinical knowledge base, but they expand it. Yet for a few family physicians, problems exist with their ability to maintain their knowledge base even at the level of the newly graduated resident. Although these distributions cannot speak to why this happens, they can demonstrate that the problem exists. Overall, the recertifiers do tend to score higher, but they do so by taking responsibility for maintaining and advancing their skills. With their additional experience, they can fly higher, but they do so without the safety net of residency. In those cases where they fail to maintain their knowledge base, they fall further than those who are just completing their residency.

\section{References}

1. O'Neill TR, Puffer JC. Maintenance of certification and its association with the clinical knowledge of family physicians. Academic Medicine 2013;88:780-787.

2. Cruft GE, Humphreys JW Jr, Hermann RE, Meskauskas JA. Recertification in surgery, 1980. Archives of Surgery 1981;116:1093-1096.

3. Choudhry NK, Fletcher RH, Soumerai SB. Systematic Review: The Relationship between Clinical Experience and Quality of Health Care. Annals of Internal Medicine 2005;142:260-273.

4. Leigh TM, Young PR, Haley JV. Performances of family practice diplomates on successive mandatory recertification examinations. Academic Medicine 1993;68:912-919.

5. Lipner RS, Song H, Biester TW, Rhodes RS. Factors that influence general internists' and surgeons' performance on maintenance of certification exams. Academic Medicine 2011;86:53-58.

6. Meskauskas JA, Webster GD. The American Board of Internal Medicine recertification examination: Process and results. Annals of Internal Medicine 1975;82: 577-581.

7. Norcini JJ, Lipner RS, Benson JA Jr, Webster GD. An analysis of the knowledge base of practicing internists as measured by the 1980 recertification examination. Annals of Internal Medicine 1985;102:385389.

8. Rhodes RS, Biester TW. Certification and maintenance of certification in surgery. The Surgical Clinics of North America 2007;87:825-836, vi. 